\title{
Enseñar a leer y escribir en las disciplinas. Estado de la cuestión en las universidades colombianas
}

\author{
Teaching to Read and Write within the Disciplines. \\ State of the Art in Colombian Universities \\ Ensinar a ler e escrever nas disciplinas.
Estado da questão nas universidades colombianas
}

Ilene Rojas García ${ }^{1}$

\section{Resumen}

En este documento se revisan cuarenta y dos trabajos de investigación que muestran los avances logrados por las universidades colombianas con respecto a la enseñanza de la lectura y la escritura en las disciplinas específicas de los programas académicos. En primer lugar, se explora el concepto de alfabetización académica como orientador de los estudios realizados; posteriormente, se identifica el papel de los actores educativos, en especial los maestros de lengua y los docentes disciplinares. Se exploran además los intereses investigativos, en cuanto al área del saber, los textos utilizados y las exploraciones que se adelantan tanto a nivel de lectura como de escritura. Finalmente, se revisan los autores con mayor índice de citación y los enfoques teóricos que subyacen a las propuestas. Se concluye que es necesario adelantar investigaciones encaminadas al análisis de los géneros académicos cuyos resultados permitan establecer propuestas didácticas y mecanismos de formación de maestros disciplinares. Tales estudios requieren una base lingüística y etnográfica que permita poner en evidencia las relaciones ideológicas que subyacen a los textos académicos.

Palabras clave

Alfabetización académica, educación superior colombiana, formación profesional

Abstract

This paper reviews forty-two research papers that analyze the progress made by Colombian universities regarding the teaching of reading and writing within specific disciplines of different academic programs. First, it explores the concept of academic literacy that guides the realization of studies; subsequently, it highlights the role of educational actors, especially language teachers and disciplinary teachers. Research interests are also explored in relation to the area of knowledge, the texts used, and studies carried out in both reading and writing. Finally, the paper reviews the most cited authors as well as the theoretical approaches that are the basis of the proposals. The study concludes that further research is necessary to analyze academic genres whose results allow to establish educational proposals and training mechanisms for disciplinary teachers. Such studies require a linguistic and ethnographic basis to expose the ideological relations that underlie academic texts.

Keywords

Academic literacy, Colombian higher education, professional training

Resumo

Neste documento são revisados quarenta e dois trabalhos de pesquisa que evidenciam os avanços conseguidos pelas universidades colombianas em relação com o ensino da leitura e a escrita nas disciplinas específicas dos programas acadêmicos. Em primeiro lugar, é explorado o conceito de alfabetização académica como orientador dos estudos realizados; após, é identificado o rol dos atores educativos, especialmente os professores de língua e os docentes disciplinares. São explorados, além disso, os interesses investigativos, em relação com a área do saber, os textos utilizados e as pesquisas em desenvolvimento tanto a nível de leitura como de escrita. Finalmente, são revisados os autores com maior índice de citação e as abordagens teóricas que subjazem às propostas. Como conclusão, é necessário realizar investigações encaminhadas à análise dos gêneros acadêmicos cujos resultados possam estabelecer propostas didáticas e mecanismos de formação de maestros disciplinares. Esses estudos requerem de uma base linguística e etnográfica que possibilite evidenciar as relações ideológicas que subjazem aos textos académicos.

Palavras chave

Alfabetização acadêmica, educação superior colombiana, formação profissional.

Artículo recibido el 9 de noviembre de 2015 y aprobado el 5 de agosto de 2016

1 Doctorado en Educación. Universidad del Norte, Barranquilla, Colombia. Correo electrónico: zellene7@gmail.com. 


\section{Introducción}

La preocupación por formar en lectura y escritura a los estudiantes que ingresan a la Educación Superior ha sido una constante de las universidades colombianas en los últimos años. En su mayoría, estos procesos se manifiestan en cursos al inicio de la carrera, enfocados hacia el desarrollo de estrategias para la comprensión y producción de textos académicos que "abordan atributos parciales del lenguaje propedéuticamente, es decir, como preparatorios del futuro uso completo y situado" (Carlino, 2013, p. 362).

Las revisiones realizadas a estos ejercicios didácticos demuestran que no parecen ser suficientes para la formación de lectores críticos y escritores intencionales. Así, la Red de Lectura y Escritura en la Educación Superior (REDLEES) (citada por Henao y Londoño, 2014), al indagar sobre la visión de los estudiantes en relación con los cursos de lenguaje, encuentra que

... no permiten tomar conciencia sobre la importancia de la lectura, que sus contenidos están aislados de las necesidades que afrontan en las asignaturas, que son genéricos, poco específicos y difícilmente aplicables; además, no hay transferencia hacia los otros cursos de las carreras (p.31).

En el mismo sentido, López y Molano (2007) consideran que los esfuerzos realizados en los cursos de comunicación oral y escrita "parece que se estuvieran perdiendo, puesto que los conocimientos allí impartidos no se refuerzan ni se exigen, como sería deseable, en las otras materias". Esto es así, porque "un curso de dos horas no es suficiente para subsanar los vacíos que traen los estudiantes de la escolaridad anterior" (Henao et al., 2011, p. 73); y porque si no existe una referencia directa a aquello que se hace y que se requiere en cada programa, la labor de los departamentos de lengua puede resultar improductiva (González y Vega, 2010).

Morales y Restrepo (2010) presentan una polémica sobre la concepción de los cursos de lengua, específicamente los de gramática y redacción en los primeros semestres, que reflejan un menor énfasis en la formación disciplinar y un mayor enfoque hacia el lenguaje como herramienta. Los autores refieren que, desde el punto de vista de algunos docentes, "se coarta la libertad al amarrarlo a las normas de la denominada 'correcta escritura"; mientras que para los docentes de lengua, los cursos "garantizan unos mínimos requeridos para que los alumnos se puedan comunicar coherentemente y sin los vicios adquiridos por las nuevas tecnologías y los usos incorrectos del lenguaje desde los medios de comunicación". $\mathrm{Al}$ respecto, los autores comparten los planteamientos de Carlino (2005) y afirman que "la lectura y escritura deben estar ligadas a los saberes disciplinares en la medida en que se conciben como prácticas socioculturales que se alteran, modifican y complejizan de acuerdo con los ámbitos en los que se inscriben" (Morales y Restrepo, 2010, p. 127). Así, argumentan que la lectura y la escritura deben tener un fin para los estudiantes, que se evidencie en lo que ellos hacen después de leer: si los estudiantes no encuentran esa finalidad en la lectura, no hay motivación y no se potencia la comprensión ni la producción. Frente a este hecho, Osorio y Arias (2014) resaltan la importancia de realizar procesos de aprendizaje de lectura y de escritura a través de las disciplinas, con el objeto de aprender a manejar la información específica de cada área del conocimiento.

Por tanto, en el presente texto se revisan los avances y resultados de investigaciones registradas principalmente en ponencias o artículos de revista de los últimos diez años. Los documentos dan cuenta de los esfuerzos docentes en las universidades colombianas por promover el desarrollo de procesos de lectura y escritura en relación directa con las disciplinas académicas de cada programa particular. Es de señalar que estos esfuerzos aparecen como estrategias regularmente aisladas de docentes interesados en el tema, pero no parecen enmarcarse en procesos de investigación amplios y sistemáticos. El análisis se centra entonces en identificar los procesos metodológicos y los referentes teóricos utilizados, que contribuyen a superar la necesidad del doble conocimiento de la lengua y del saber científico, así como las posibilidades de 
trabajo colaborativo y las políticas institucionales que fomentan estos procesos.

Para ello se usó la base de datos de la Universidad Tecnológica de Pereira, construida por Cisneros (2014), quien recoge más de 1600 trabajos de investigación referidos a la lectura y la escritura en la universidad. Entre estos documentos, aquellos centrados específicamente sobre experiencias en las disciplinas son pocos, en su mayoría corresponden a artículos presentados como ponencias en eventos académicos, especialmente los organizados por la Cátedra UnEsCo, REDLEEs, la Universidad del Valle y la Universidad del Norte. A nivel de trabajos de grado relacionados con el tema, solo aparecen los elaborados por Camargo (2006) de la Universidad del Quindío y Morales y Restrepo (2010) del Politécnico Grancolombiano. En cuanto a libros, se encuentra el documento elaborado por Cisneros y Muñoz (2014) como un inventario realizado al material bibliográfico de publicaciones en lectura y escritura entre 1990 y 2012. Se encuentra también la obra de González y Vega (2010), allí las autoras abordan de manera detallada el tema de la alfabetización académica desde su concepción por parte de los actores educativos, hasta los procesos de intervención en las aulas en las distintas asignaturas de la Universidad Sergio Arboleda. Cabe mencionar la investigación de Pérez y Rincón (2013), que constituye uno de los principales referentes acerca de la forma en que se lee y se escribe en las universidades colombianas. Si bien este trabajo no discrimina las prácticas textuales según cada campo del saber, permite reflexionar a nivel nacional sobre el manejo de estos procesos; además, fue construido con la participación de diversas universidades y retomado por otros autores como punto de partida para nuevas investigaciones.

\section{Concepto de alfabetización académica}

El primer segmento de análisis en los documentos abordados fue el concepto base de alfabetización académica. En 17 de los 42 documentos estudiados se retoma la definición de Carlino publicada en el 2005. En las restantes investigaciones aparecen otros acercamientos teóricos acerca de la enseñanza de la lectura y la escritura que actúan como orientaciones teóricas y metodológicas para guiar las prácticas de aula. Ambos aspectos serán discutidos en el presente apartado.

Para Carlino, la alfabetización académica se entiende como una "acción socialmente situada que responde a formas particulares de significación", relacionada directamente con

... las nociones y estrategias necesarias para participar en la cultura discursiva de las disciplinas así como en actividades de producción y análisis de textos requeridos para aprender en la universidad. Apunta a las prácticas de lenguaje y pensamiento propias del ámbito académico superior. (2005, p. 13)

Esta definición es retomada literalmente por siete de las investigaciones revisadas.

Ocho años después, Carlino revisa el concepto y lo replantea a la luz de las distintas investigaciones adelantadas en universidades tanto anglófonas como latinoamericanas. Así, sostiene que la alfabetización académica se refiere a los procesos pedagógicos que tienen como fin promover el acceso de los estudiantes universitarios a las prácticas letradas propias de su campo del saber; se relaciona con la capacidad para "exponer, argumentar, resumir, buscar información, jerarquizarla, ponerla en relación, valorar razonamientos, debatir, etcétera, según los modos típicos de hacerlo en cada materia" (Carlino, 2013, p. 370). Además, la alfabetización académica incluye dos objetivos: 1) Enseñar a comprender y producir los géneros propios de su campo del saber, como lo hacen los especialistas; y 2) Enseñar las prácticas de estudio necesarias para apropiarse de los conceptos propios de la disciplina. Dado que ambos objetivos se inscriben directamente en la especificidad de cada campo, se infiere una obligatoriedad de los procesos de enseñanza por contextualizar las prácticas en las asignaturas y a lo largo de la carrera. Lo anterior deja por fuera la enseñanza de habilidades escindidas de los objetivos específicos de formación en cada área del saber (2013).

Como se ve, Carlino pasa del concepto de “acción” al de "proceso de enseñanza", resaltando el 
carácter didáctico de la alfabetización en la universidad; además, puntualiza en lo que ha de entenderse por producción y análisis de textos, presentando una serie de acciones que deben llevar a cabo los estudiantes universitarios. Finalmente, rescata los objetivos que ya había mencionado en otros de sus estudios (2010, 2011), enfilando la alfabetización tanto al dominio del saber como a la apropiación del discurso. Esta última definición, mucho más elaborada que la anterior, apenas está cobrando reconocimiento en Colombia y aparece solo en dos de los documentos estudiados.

Puesto que la alfabetización académica claramente implica procesos de lectura y escritura, coexisten con esta definición otras que gravitan alrededor del dominio del texto escrito y orientan las prácticas de aula hacia otros objetivos paralelos a la formación profesional. Así, RedLeEs (2014) subraya su relación directa con temas como la calidad de la educación, la equidad, la cobertura; el fortalecimiento de la investigación para la producción de conocimiento; el impulso de la cultura; el desempeño académico de los estudiantes, su permanencia en la universidad y sus competencias laborales. Perspectivas como las de Cadena, Narváez y Chacón (2007) resaltan también el proceso de formación académica y ciudadana a través de la lectura y la escritura, mientras que Ortega y Sánchez (2002) resaltan el desarrollo de la mente. Sin embargo, el común denominador sobre la concepción de alfabetización académica es el relacionado con el acceso al saber que garantizará su permanencia en la universidad y el adecuado desempeño profesional.

Los investigadores referencian también las concepciones existentes en el entorno que entienden la enseñanza de la lectura y la escritura en la universidad como la posibilidad de suplir las deficiencias resultantes de la Educación Básica. Se considera que estas habilidades "se adquieren en ciclos iniciales y simplemente se ponen en funcionamiento en la formación profesional, lo que aparentemente revela que la formación disciplinar está separada, o no se percibe, como integrada a prácticas de lectura y escritura" (Morales y Restrepo, 2010, p. 88). Si se entiende la formación en lengua materna como responsabilidad de la Educación Básica o de los cursos iniciales universitarios, es clara la poca preocupación de muchos docentes por vincular estos procesos directamente en el aula. Así, el estudio de González y Vega (2010) coincide con el de otros autores en diversos países cuando afirma que en el nivel superior predomina el método de sugerir lecturas y evaluar su contenido sin un acompañamiento permanente al proceso.

Sin embargo, aunque muchas de las investigaciones que se adelantan en el país se dirigen hacia este tipo de procesos remediales, es evidente la preocupación de otros por vincular las áreas disciplinares en el trabajo con el texto escrito, de una manera más cercana a la propuesta por Carlino. De allí que presenten distintos argumentos a través de los cuales se justifica su enseñanza en relación directa con los programas académicos universitarios. En primer lugar, Morales y Restrepo (2010) reflexionan en torno al concepto de lectura y escritura como habilidades o competencias; sostienen que no pueden ser entendidas de esta manera puesto que dentro del contexto académico, el texto escrito se sitúa en los saberes particulares que "requieren de una apropiación y de un trabajo de deconstrucción y reconfiguración del pensamiento, la práctica y la ideología que se reproducen con los discursos disciplinares". Esto quiere decir que, bajo el concepto de competencia acunado por Chomsky (1965) sobre el lenguaje como habilidad innata, la capacidad del dominio del texto académico demanda un aprendizaje situado y consciente que permita acceder al dominio de la disciplina, no solo a nivel conceptual, sino también de configuración del pensamiento especializado de la disciplina académica en la que se inscribe el estudiante y la significación en las comunidades científicas.

Asimismo, Duque (2007) presenta la lectura como un

... proceso permanente de interpretación, superando las barreras de lo literal (interpretación denotativa o explícita) del texto para ingresar en un plano crítico (connotativo, en busca de la 
información implícita mediante procesos inferenciales), para asumir una posición frente a los textos y frente a sus intenciones; para establecer relaciones intertextuales y generar procesos argumentativos. (p. 4).

En este sentido, es claro que las habilidades de comprensión pueden ser trabajadas a partir de cualquier tipo de texto, pero utilizar documentos de las disciplinas específicas contribuye, no solo a generar mayor interés en los estudiantes, sino además les permite adquirir los saberes que requieren en su formación, así como establecer relaciones entre las construcciones discursivas y los usos reales del texto en el ámbito científico en el que se forman.

Por otro lado, se resalta la función epistémica de la escritura, desde donde se concibe la producción de textos académicos en relación directa con los conocimientos propios de cada disciplina (Mateos et al., 2008). Esto involucra el aprendizaje directamente con el proceso escritor, en tanto que, de un lado, dominar el lenguaje escrito facilita el acceso al saber, pero también se requiere textualizar los conocimientos a la manera como se hace en la comunidad académica con el fin de estructurar los procesos mentales y aportar al saber científico. Asimismo, en los documentos objeto de estudio aparecen investigaciones que subrayan el impacto del texto escrito tanto en el cambio conceptual del estudiante (Escobar, 2014; Pedraza y Cabrera, 2014) como en la reconstrucción del saber académico (Coronado y Barragán, 2007).

En este sentido, Ortega y Sánchez (2002) subrayan la forma como la escritura incluye subprocesos de planificación, textualización, revisión, evaluación y control del proceso; además, "en sus aspectos sociales constituye un medio de comunicación y de participación en comunidades de discurso específicas, académicas, científicas, disciplinares". De esta manera, existe una preocupación en torno a los procesos escritos, como por ejemplo la toma de apuntes de los estudiantes, debido a que constituye una de sus principales fuentes de estudio (Molina, 2014) o la elaboración de resúmenes como método de aprendizaje (Ramírez y López, 2014). Interesa resaltar además el trabajo de Cuesta, Rodríguez y Sandoval (2014) en relación con los géneros médicos: los autores retoman el trabajo de PosteguíPique (2006) y describen la forma en que la escritura permite la interacción con los pacientes, a nivel de la práctica, y con los compañeros, a nivel de la investigación. Esto tiene relación directa, no solo con el aspecto formal de las normas de la lengua, sino con el propósito con el cual se usa el lenguaje, de acuerdo con la audiencia y con el desarrollo de las ideas.

Por otro lado, con respecto a la didáctica de la lengua, las investigaciones consultadas, la conciben como un mecanismo para desarrollar el pensamiento y generar una conciencia crítica. En este sentido, Duque (2007, p. 4) evita la visión mecánica de la escritura y la presenta como un proceso complejo de producción de pensamiento, incluyéndola en el aprender a pensar; Henao y otros (2011, p. 62) la entienden como una capacidad para "actualizarse e innovar"; y Gómez (2015, p. 7) la utiliza como mecanismo para desarrollar el pensamiento crítico en estudiantes de periodismo.

Ahora bien, cabe preguntarse si son necesarios esfuerzos en ambos frentes: desde la apropiación general de la lengua en los cursos iniciales y desde el dominio especializado del discurso de la disciplina. Al respecto, Narvaja (2010, p. 8) sostiene que las instituciones de educación superior deben promover las actividades de lectura y escritura al interior de las diferentes disciplinas académicas; sin embargo esto no es suficiente. También es indispensable preparar a los estudiantes para entrar en contacto con los múltiples discursos sociales que exceden el campo disciplinar y que requieren de una actitud crítica propia de ciudadanos conscientes. En el mismo sentido, aparecen los textos propios de cada campo profesional sobre los cuales los estudiantes no han transitado antes, para los cuales deberán apelar a los conocimientos que tengan sobre la discursividad en general. Por tanto, las habilidades para leer y escribir en estos tres frentes, no pueden ser adquiridas en un solo espacio académico, sino en la confluencia de múltiples tareas destinadas a la reflexión sobre 
el lenguaje, con el objeto de adquirir la autonomía necesaria.

Las investigaciones consultadas, centradas en el espacio disciplinar, permiten afirmar que las herramientas de lectura y escritura, el acceso al saber, el desarrollo del pensamiento crítico y el ejercicio de la ciudadanía, pueden ser desarrollados conforme se abordan textos disciplinares en las asignaturas específicas con el acompañamiento del docente de lengua. Así se demuestra en el estudio de Cuesta et al. (2014):

Escribir no sólo es aprender a usar buena ortografía, gramática y seguir los lineamientos legales sobre el diligenciamiento de las historias clínicas, es también, reconocer que en este tipo de texto hay una organización de la información, una manera de presentarla, una estructura simple en la composición de las oraciones que están ligadas al tipo de texto expositivo-descriptivo en el que podría considerarse se encuentra la historia clínica. (p. 3)

Una propuesta interesante que busca garantizar el proceso desde las generalidades del texto hasta su especificidad en textos profesionales es elaborada por Pérez (2006) para la formación en el área de la medicina. Allí el investigador propone un plan de estudios para la asignatura "Comunicación" durante cuatro semestres consecutivos; inicia con procesos de interpretación y producción textual, analiza la relación médico-paciente en la historia clínica y finaliza con la cortesía lingüística y la interlocución con la comunidad.

Es clara entonces la obligatoriedad de la gramática y la ortografía, así como las habilidades generales para la comprensión y producción de textos; pero también es necesario resaltar la necesidad de vincular estos conocimientos con su uso real en situaciones de aprendizaje disciplinar, de modo que, de un lado, se trascienda en el reconocimiento del género discursivo en el que se incluyen las intencionalidades, las formas de uso y las construcciones textuales relacionadas con ellas. Por otro, se hace posible evitar el Efecto Mateo (Stanovich, 1986) según el cual, la falta de experiencias de lectura retrasa el desarrollo de la automaticidad y de la velo- cidad en el reconocimiento de las palabras; cuando estos procesos son lentos, consumen los recursos cognitivos que deberían asignarse a la comprensión, lo cual ocasiona mayores falencias.

Ahora bien, si se trata de enseñar lengua en el marco de la disciplina. ¿quién debe hacerlo? ¿el profesor de lengua que conoce el sistema? ¿o el docente de la disciplina, inmerso en el contexto científico de cada campo? En el siguiente apartado se da cuenta de las concepciones que, en este sentido, aparecen en las investigaciones consultadas.

\section{El compromiso de los actores educativos frente a la alfabetización académica}

Los docentes en los documentos revisados asumen el compromiso de enseñar a leer y escribir en relación directa con los conocimientos específicos de cada campo del saber; en ocasiones, este trabajo logra realizarse en equipo entre el docente de lengua y el de la disciplina (Calle, 2015; De Castro y Cols, 2015; Echeverri, 2015; Ramírez y López, 2014). Esta sinergia permite incluir tanto los conocimientos lingüísticos como los contextos discursivos y conceptuales de los saberes especializados, así como las necesidades reales de comunicación en el entorno académico. Tales posibilidades de trabajo continúan siendo esfuerzos aislados de docentes que, conscientes del papel del lenguaje en el aprendizaje, suman saberes, tiempos y espacios para crear y ejecutar propuestas de intervención en el aula. Pero extender estas experiencias a lo largo de la educación superior requiere la movilización de recursos logísticos a nivel institucional que dependen más de organismos administrativos independientes del ejercicio docente. En este sentido, las investigaciones objeto de revisión inician pasando revista a los inconvenientes y posibilidades de la alfabetización académica.

Por lo regular se encuentra una falta de acompañamiento de los docentes de las disciplinas cuando vinculan el texto escrito como estrategia metodológica para el aprendizaje o la reflexión. La investigación de Pérez y Rincón (2013, p. 200) demuestra 
cómo en los distintos programas universitarios el docente de la disciplina asigna tareas de lectura y escritura sin enseñar a establecer las relaciones que ellos solicitan y esperando el cumplimiento con calidad de los procesos. Resultados semejantes aparecen en el trabajo de López y Molano (2007, p. 140), quienes sustentan que muchos profesores no son claros en determinar el tipo de texto que los estudiantes deben presentar, y es solo una mínima parte de los docentes quienes se preocupan por acompañar estos procesos. En la misma línea, González y Vega (2010, p. 70) afirman no encontrar estrategias de argumentación, comparación o puesta en diálogo de teorías, ni tampoco se contextualizan las fuentes bibliográficas ni sus sistemas de referencias; los documentos aparecen como fragmentos de ideas específicas que serán luego complementadas con la explicación del profesor. Esto impacta en las concepciones de los estudiantes, quienes asumen las lecturas como una serie de datos sobre los cuales no se reflexiona intencionalmente en relación con el contexto cultural y académico en el que se inserta el saber científico.

De allí que el bajo rendimiento de los estudiantes responde también a esta falta de acompañamiento de los docentes disciplinares, que deja en ellos ejercicios reducidos de análisis, comparaciones o relaciones entre autores, insuficientes para generar nuevo conocimiento (Morales y Restrepo, 2010, p. 60). Asimismo, el hecho de esperar que los estudiantes respondan por ellos mismos a los requerimientos académicos, da cuenta de la concepción común, ya mencionada, según la cual, la responsabilidad por la formación en lectura y escritura recae únicamente en los docentes de lengua, especialmente de la educación básica, pues se formulan tareas que se asumen adquiridas en esta etapa de la escolaridad.

Dentro de las investigaciones, es posible encontrar también la forma de explicar tales falencias. En el documento de González y Vega (2010, p. 50) se hace referencia al poco tiempo con el que cuentan los docentes de las disciplinas para emprender procesos de acompañamiento a las tareas de lectura y escritura. Por su parte, Cadena, Narváez y Chacón
(2007, p. 2) y Rojas (2014a, p. 92) lo justifican desde el desconocimiento del docente de la disciplina sobre cómo establecer procesos de mediación en las tareas relacionadas con el texto escrito. Mientras que Molina (2014, p. 11) sostiene que los profesores no son conscientes de la función epistémica de los apuntes de clase y su papel en el aprendizaje de contenidos.

La situación se agrava ante la escasa investigación desde una visión sociolingüística (Cisneros y Muñoz, 2014) que ponga en evidencia la relación entre los usos particulares de la lengua en los distintos campos del saber y las particularidades discursivas que responden a estos usos. Se resalta entonces la necesidad primordial de capacitar a los docentes, de modo que les sea posible afrontar la variación lingüística de su disciplina, delimitar fenómenos discursivos y textuales, definir problemas, puntualizar dificultades y orientar en el ejercicio de diferentes modos de leer y de escribir (Narvaja, 2010, p. 7). En esa medida, se abrirán "alternativas para que el estudiante pueda abordar problemas académicos, expresar su mundo conceptual y desempeñarse en su ejercicio cognoscitivo y comunicativo, aun en posesión de su propia variante lingüística" (Cisneros y Muñoz, 2014, p. 25).

Frente a estas problemáticas, los investigadores buscan mecanismos de mejoramiento orientados a intervenir tanto en las actuaciones docentes como en el aprendizaje de los estudiantes y su manejo del texto escrito. El problema es presentar una forma de lectura y escritura como la precisa para un espacio o una disciplina y comprometer a todos con ese requerimiento (González y Vega, 2010, p. 83), haciéndola parte integral del proyecto pedagógico de las asignaturas. Si el docente disciplinar hace énfasis en los contenidos y el docente de lengua domina los procesos de comprensión y producción textual, se hace evidente la necesidad del trabajo colaborativo entre ambos, de modo que sea posible establecer una transposición didáctica tanto del saber especializado como del conocimiento del texto escrito.

Así lo proponen investigaciones como las de Peña (2007), Rojas (2013), Pedraza y Cabrera (2014). 
Allí se resalta la importancia de acompañar a los estudiantes tanto desde la clase de lengua como desde las asignaturas disciplinares, de modo que se promueva el aprendizaje autónomo que le permita al estudiante, principalmente, dominar el texto escrito, y a partir de allí, aprender por sí mismo los conocimientos que, por falta de tiempo, no pudo adquirir en el espacio curricular. Se propone también un trabajo donde se incluyan las lecturas de las asignaturas disciplinares al interior de la clase de lengua que potencie, tanto la adquisición de conocimientos disciplinares como los mecanismos para la comprensión y producción de textos (Rojas, 2015), resaltando siempre el saber, el pensar y la producción de conocimiento (González y Vega, 2010, p. 116), de modo que la lectura y la escritura involucren la reflexión acerca de los puntos de vista y las construcciones discursivas de los autores que se abordan. Además, Morales y Restrepo (2010, p. 105) enlistan una serie de objetivos de los cursos de lectura y escritura en las asignaturas, que pueden entenderse como complementarios y pertinentes para los espacios curriculares de cada disciplina: Producir textos propios de las disciplinas, comprender contenidos y textos disciplinares, desarrollar el pensamiento crítico, aprender aspectos formales de la lengua, apoyar procesos investigativos, suplir deficiencias de los niveles anteriores y desarrollar estrategias metacognitivas. Cabe resaltar que el logro de estos objetivos implica el trabajo colaborativo de los distintos organismos institucionales.

La revisión de los documentos objeto de estudio pone en evidencia que las directrices institucionales orientadas a la formación en lectura y escritura desde el trabajo interdisciplinar, aún tienen un largo camino por recorrer. En su mayoría, se proponen cursos generales o, incluso, lecturas generales, elegidas por su relación con los contenidos de las áreas disciplinares, pero no se encuentra un vínculo directo con las demás actividades de formación, sino que se propone de manera paralela al programa académico. Los esfuerzos denodados de los maestros de lengua al interior de las distintas disciplinas aparecen como un ejercicio individual de reflexión e intervención por pequeños grupos de docentes movidos por intereses particulares quienes, solo en ocasiones, encuentran apoyo en sus pares de otras áreas del saber. En el siguiente apartado, se ampliará la exploración en este sentido, prestando especial atención a los esfuerzos por la enseñanza de la lengua en programas como Medicina, Derecho, Comunicación Social, Psicología, Licenciatura, Ingeniería, Tecnología, Negocios y Arte, facultades en las que se inscriben las investigaciones consultadas.

\section{Los textos y los intereses investigativos en las propuestas de alfabetización académica}

En los documentos sobre lectura y escritura desde las disciplinas se encuentra regularmente una referencia al papel del docente, la situación de los estudiantes, las estrategias de intervención didáctica y la revisión teórica; pero se ha profundizado poco en la descripción y análisis de los distintos géneros textuales utilizados para aprender y reflexionar en torno a las disciplinas específicas. Algunas investigaciones se limitan a hacer una mención genérica para mostrar que se leen ciertos títulos; este es el caso de los trabajos de Coronado y Barragán (2007), Manyoma y Gómez (2013) y Parra (2013), quienes involucran el concepto de Plan Lector como un mecanismo para institucionalizar el proceso de lectura y escritura en la universidad. Sin embargo, si bien los distintos textos que proponen deben ser estudiados por todos los alumnos según su enfoque disciplinar, no se evidencia claramente en los artículos una revisión cuidadosa de los textos, a nivel discursivo ${ }^{2}$ en relación directa con los contenidos curriculares de las asignaturas, sino que tal relación se presenta más desde el nivel temático de los documentos elegidos. Esto genera una revisión del texto escrito desde lo anecdótico, promoviendo mecanismos de reflexión y crítica pero sin acudir a procesos de análisis a nivel discursivo y textual. En cuanto a la especificidad de las disciplinas,

2 Se entiende el nivel discursivo como una práctica social donde los participantes interactúan a partir del uso lingüístico contextualizado, es decir, la comunicación verbal implica reconstruir las piezas textuales que se orientan a fines determinados en relación directa con el contexto. Tal interacción genera una relación dialéctica en donde el contexto da forma al discurso, y al mismo tiempo, el discurso configura el entramado social (Calsamiglia y Tusón, 1999, p. 15). 
(Morales y Restrepo, 2010, p. 86) mencionan la crónica, el reportaje, la noticia y la columna periodística, como los textos que más se leen en la Facultad de Comunicación Social, precisamente porque hacen parte inherente del trabajo que desempeñarán estos profesionales; sin embargo, tampoco se adelanta una revisión del nivel discursivo de los textos ni sus implicaciones en la comprensión, la producción y el desarrollo de la capacidad crítica.

Dentro de los trabajos que describen las características de los textos usados en la universidad, se encuentra el de Cadena, Narváez y Chacón (2007, p. 11), quienes retoman los textos sugeridos por los docentes de Fundamentos de Economía e Introducción a la Ingeniería, para dar cuenta de sus características discursivas y, en esa medida, identificar el nivel de complejidad de los documentos que deben leer los estudiantes. El interés de este análisis radica en que los docentes de las asignaturas mencionadas consideran que el aprendizaje se produce de manera más sencilla si los textos son fáciles de leer, pero las autoras revelan que casos como las reiteraciones por superordenación y generalización atribuyen mayor densidad textual y por tanto, mayor dificultad para la comprensión. Este tipo de reiteraciones solo son identificadas por los estudiantes en la medida en que su saber previo se los permita.

También a nivel de las características textuales que pueden ocasionar dificultades para la comprensión de los estudiantes, se encuentra el trabajo de Rojas (2014a), centrado específicamente en el área del Derecho. En los textos revisados aparecen aspectos como la necesidad de saberes previos, el uso de recursos retóricos, la abundancia de incisos explicativos extensos que aumentan la densidad conceptual, la terminología especializada, ambigüedades en los referenciales y los deícticos, la negación múltiple y la ausencia de conexiones explícitas. Se subrayan además aspectos como la ejemplificación, los paratextos, la cotextualización o la idea central explícita, como mecanismos auxiliares para la comprensión.

Interesa resaltar el trabajo de Gordillo y Restrepo (2014), quienes vinculan el lenguaje escrito como parte esencial para la enseñanza de las matemáticas en el programa de Administración de Empresas y Contaduría. Su objetivo es determinar los niveles de comprensión de textos que tratan las ecuaciones algebraicas elementales. Para ello promovieron en los estudiantes la conversión del lenguaje simbólico matemático en expresión oral lingüística, y evaluaron los procesos de segmentación y recontextualización, es decir, la descomposición del texto en unidades textuales y de información, así como el establecimiento de conexiones implícitas entre dichas unidades. Encontraron que los estudiantes tienen vacíos en los campos semánticos asociados que les dificulta comprender el texto para dar cuenta del conocimiento sobre las ecuaciones algebraicas elementales.

La investigación adelantada por Manyoma (2015) ha identificado claramente los textos que se abordan en las disciplinas para iniciar su proceso de intervención, entre ellos se cuenta el informe, la relatoría, la reseña y el artículo de investigación, entre otros. En el estudio de Pérez y Rincón (2013, p.132.148), se mencionan los textos utilizados frecuentemente en el aula, entre los que se cuentan las lecturas para aprender como libros o capítulos propios del campo profesional, lo cual demuestra la lectura como una apuesta didáctica orientada a aprender leyendo los fundamentos teóricos de la profesión. También predomina la lectura de apuntes de clase (escritos por los mismos estudiantes), materiales elaborados por el profesor y blogs. Desde la escritura aparecen con mayor índice de recurrencia, nuevamente los apuntes de clase, y también resúmenes, ensayos e informes. Si bien el documento explica los motivos e implicaciones de esta recurrencia, es en el trabajo de Molina (2014) donde se avanza en una somera descripción de los textos escritos por los estudiantes de los distintos programas académicos cuando deben tomar apuntes de clase. Dentro de sus hallazgos se encuentra que

en Medicina, los apuntes tienden a ser más literales y extensos; no se reconoce fácilmente una reelaboración por parte del estudiante ante la información presentada, pues fundamentalmente se limitan a anotar cifras y datos exactos o conceptos irrefutables. En la clase de Ingeniería 
Electrónica se presentan apuntes cuyo contenido radica casi totalmente en las cifras, fórmulas, ecuaciones o gráficos. El contenido narrativo de los apuntes y la construcción de discurso por parte del estudiante es casi inexistente, más allá de alguna frase para recordar algo muy puntual. Finalmente, los apuntes de clase de Comunicación evidenciaron que los registros son mucho más puntuales y concretos. Sobresalen las notas cuyo principal objetivo es resumir el planteamiento de un postulado o recordar el nombre de los autores teóricos que el profesor utiliza como apoyo. (p. 10)

Ahora bien, desde los requerimientos de los docentes de las disciplinas, López y Molano (2007, p. 134) identificaron en tres programas académicos (Economía y Negocios Internacionales, Ingeniería de Sistemas y Derecho) la necesidad de que los estudiantes aprendan a "usar habilidades cognitivolingüísticas como describir, analizar, sintetizar, definir, explicar, comparar, inferir, valorar". Con respecto a las áreas particulares, las expectativas de los docentes en cada programa son diferentes: en Derecho, conciben la escritura como un registro, pues desean que los estudiantes den cuenta de lo que leen. En cambio, los profesores y estudiantes de Economía son conscientes del papel trascendental de la escritura en la construcción de saberes. Los de Ingeniería de Sistemas, por su parte, dejan ver que para ellos lo importante es que los estudiantes demuestren que manejan los temas y fundamentos técnicos, propios de la ingeniería, lo cual lleva a pensar que le están dando más valor al manejo de la temática que a la escritura académica como tal (López y Molano, 2007, p. 138).

También en relación con la escritura, desde la facultad de Comunicación Social, Gómez (2015, p. 6) encuentra especialmente relevante el ejercicio de escritura a partir de las teorías del análisis crítico del discurso, pues los estudiantes de semestres avanzados imitan el tono de la voz periodística que leen, y con ello están reproduciendo también la ideología a favor del poder. Por ello, emprende un análisis del texto periodístico a la luz del enfoque crítico discursivo, que permita crear conciencia sobre el uso del lenguaje en el oficio particular del periodismo. Por su parte, Cuesta et al. (2014), en un trabajo con estudiantes de últimos semestres de medicina, identifican el tipo de textos que deben escribir. El objetivo es orientar la escritura, no solo hacia el aspecto formal, sino también pragmático en el uso de la lengua; en este sentido, se revisan los textos "anteproyecto" e "historia clínica". En trabajos como los de Gómez (2004), Herrera (2014), García, Nieto y Vera (2014), este interés por la enseñanza de la escritura como mecanismo de aprendizaje suele ir acompañado de un componente pedagógico fuerte, pero sin soportes lingüísticos de base que permitan trascender más allá de las estructuras formales del texto o la preocupación por la correcta escritura.

Como se ve, los textos estudiados evidencian una heterogeneidad de intereses en las investigaciones relacionadas con la enseñanza de la lectura y la escritura en las disciplinas. Estos van desde el diagnóstico sobre los documentos que se leen y se escriben en la universidad, con su respectiva revisión teórica orientada a determinar algunos de los aspectos de mayor complejidad para el dominio del texto escrito, así como los mecanismos cognitivo-lingüísticos que interfieren en la comprensión, pasan por el estudio de los objetivos de lectura y escritura específicos en algunas facultades y finalizan en la intervención a nivel institucional y las propuestas de plan lector orientadas a fomentar la reflexión.

Con todo, cabe resaltar que no es suficiente identificar los textos que se leen y se escriben en la universidad. Hace falta profundizar en sus características discursivas, no tanto para clasificarlos en alguna tipología teórica disponible (por ejemplo: narrativos, expositivos y argumentativos), sino para revisar aspectos como el propósito social, la intención comunicativa, los puntos de vista y otros elementos esenciales que permitan a los estudiantes encontrar la relación entre las prácticas de lectura y escritura, los objetivos de aprendizaje de las asignaturas y su futuro desempeño profesional. Asimismo, se demuestra que en las universidades se leen y escriben, en su mayoría, textos como los apuntes de clase (de los estudiantes) o los trabajos escritos (solicitados por los docentes) (Morales y Restrepo, 2010 y Pérez y Rincón, 2013), 
con fines y estructuras distintos, lo cual dificulta establecer procesos de enseñanza orientados bajo parámetros objetivos.

\section{Enfoques teóricos para la enseñanza de la lectura y la escritura a nivel disciplinar}

Una vez revisadas las concepciones de alfabetización académica, el compromiso generado frente a la enseñanza de la lectura y la escritura en las distintas asignaturas universitarias y los intereses que motivan las investigaciones, se procede a determinar los enfoques teóricos que sirven de base a los autores para direccionar sus trabajos. Para ello, se identificaron las obras bibliográficas más recurrentes en las referencias de los documentos, así como los enfoques teóricos que se presentan de manera explícita. En la tabla 1 se pueden observar los autores y las obras con mayor nivel de citación en los libros y artículos revisados.

Tabla 1. Recurrencia de autores y obras en las referencias de las investigaciones

\begin{tabular}{|c|c|c|c|}
\hline Autor & $\begin{array}{c}\text { Índice de } \\
\text { recurrencia } \\
(\%)\end{array}$ & Obra & $\begin{array}{c}\text { Índice de } \\
\text { recurrencia } \\
(\%)\end{array}$ \\
\hline \multirow{8}{*}{ Carlino, $\mathrm{P}$. } & \multirow{8}{*}{28,5} & $\begin{array}{l}\text { Escribir, leer y aprender en la universidad: una } \\
\text { introducción a la alfabetización académica }\end{array}$ & 8,5 \\
\hline & & $\begin{array}{l}\text { ¿Qué nos dicen hoy las investigaciones internacionales } \\
\text { sobre la escritura en la universidad? }\end{array}$ & 1 \\
\hline & & Alfabetización académica 10 años después & 1 \\
\hline & & $\begin{array}{l}\text { Alfabetización académica: un cambio necesario, } \\
\text { algunas alternativas posibles }\end{array}$ & 1 \\
\hline & & $\begin{array}{l}\text { Escribir a través del currículo. Tres modelos } \\
\text { para hacerlo en la universidad. }\end{array}$ & 1 \\
\hline & & $\begin{array}{l}\text { Enseñar a escribir en la universidad. Cómo lo } \\
\text { hacen en Estados Unidos y por qué }\end{array}$ & 1 \\
\hline & & $\begin{array}{l}\text { Escribir y leer en la universidad: responsabilidad } \\
\text { compartida entre alumnos, docentes e instituciones }\end{array}$ & 1 \\
\hline & & Otros & 14 \\
\hline \multirow{5}{*}{ Van Dijk, T. } & \multirow{5}{*}{13} & La ciencia del texto & 3,5 \\
\hline & & Estructuras y funciones del discurso & 3 \\
\hline & & Texto y contexto, semántica y pragmática del discurso & 1,5 \\
\hline & & Ideología & 1,5 \\
\hline & & Otros & 3,5 \\
\hline \multirow{5}{*}{ Cassany, D. } & \multirow{5}{*}{12} & Describir el escribir & 2 \\
\hline & & La cocina de la escritura & 1,5 \\
\hline & & Tras las líneas & 1 \\
\hline & & Prácticas letradas contemporáneas & 1 \\
\hline & & Otros & 7 \\
\hline
\end{tabular}


Como se observa, Carlino es el referente más usado por cuanto trae y adapta de la tradición anglosajona el término literacy y lo presenta como alfabetización. Con él, la autora pone en evidencia la necesidad de acompañar y didactizar procesos de lectura y escritura en la Educación Superior, pues se trata de un discurso especializado que requiere de habilidades distintas a las adquiridas durante la Educación Básica. Su amplio conocimiento en investigaciones tanto a nivel diagnóstico como de intervención en el aula, así como su dominio de estudios con mayor trayectoria en universidades anglófonas (2004b), la sitúan como una de las autoras más reconocidas en el tema. Los estudiosos colombianos buscan en sus trabajos no solo un respaldo para las investigaciones que se adelantan, sino también un referente conceptual que oriente sus reflexiones y propuestas didácticas. De allí que interesa revisar los planteamientos que se retoman con mayor recurrencia.

En principio, la autora argentina (2007) inscribe su postura en el marco de los estudios pedagógicos sobre "escribir a través del currículo" y "escribir en las disciplinas", surgidos en Inglaterra y Estados Unidos a partir de la década de los 70. Ambos se interesan por incluir la enseñanza de la escritura en las distintas asignaturas, tanto para aprender los contenidos como para dominar el discurso especializado. Esta concepción se justifica desde varias razones, expuestas por Carlino y retomadas por las investigaciones consultadas.

En primer lugar, se concibe la formación profesional como el ingreso a comunidades académicas especializadas que poseen sus propios discursos (formas de decir, propósitos comunicativos, usuarios, contextos científicos, entre otros): también denominadas frecuentemente como "culturas escritas". En este sentido, el texto escrito es visto como una práctica académica que varía según la cultura institucional, cumple una función social, política y ética, y requiere una actualización permanente (Pérez y Rincón, 2013). Por ello, aprender una determinada materia no implica solamente manejar los conocimientos, sino que trasciende a conocer y dominar distintos tipos de textos con altos niveles de complejidad (Carlino, 2002), y con usos, propósitos y usuarios específicos.

Por otro lado, las investigaciones retoman las referencias de Carlino (2005) hacia la función epistémica de la escritura, es decir, la posibilidad de actuar como herramienta para "adquirir, elaborar, transformar y comunicar el conocimiento" (López y Martínez, 2014, p. 3). Esto se comprueba en investigaciones desde la psicología cognitiva (Kintsch, 1998) que demuestran cómo la lectura permite una interacción entre el pensamiento y el lenguaje, mientras que la escritura obliga a los estudiantes a reconstruir el conocimiento y, en esa medida, adueñarse de su contenido. De allí que Carlino (2003a) propone una enseñanza basada en el modelo de Scardamalia y Bereiter (1992), tendiente a promover la reconstrucción de sistemas, conceptos y estrategias de aprendizaje de un campo de estudio, que trascienda las clases magistrales donde el docente se limita a explicar el saber y el estudiante a escucharlo.

Para lograrlo, Carlino (2005) resalta la necesidad de participar en actividades reales, vinculadas directamente con el discurso propio de las disciplinas. Señala que es indispensable leer bibliografía auténtica para estar en la capacidad de "analizar en profundidad las corrientes teóricas, apreciar la complejidad de sus racionamientos y examinar las bases empíricas en las que se apoyan. Esto no se logra ni escuchando clases ni leyendo manuales diseñados para una materia". Carlino rescata la utilidad de los manuales para organizar el campo de estudio, pero no son suficientes por cuanto filtran las complicaciones de la teoría, plantean un solo punto de vista e impiden al lector reconocer la multiplicidad de problemas no resueltos que conforman el campo de la ciencia (p. 73). Esta necesidad de realizar actividades directamente relacionadas con el contexto de la disciplina se explica en la medida en que existe una relación, muchas veces indisociable, entre pensamiento $y$ lenguaje que liga las estrategias de estudio directamente con el contexto en el que se desenvuelven, de modo que no pueden ser transferidas si se aprenden por fuera de los contenidos específicos 
(Carlino, 2003b, p. 414). Asimismo, permiten involucrar al estudiante en las prácticas que configuran la cultura académica y profesional, y facilitan el aprendizaje y el desarrollo de la competencia discursiva (Carlino, 2005). La primera razón responde a las teorías del aprendizaje situado, y la segunda, a la concepción de leer y escribir como prácticas sociales.

La idea es, entonces, generar un aprendizaje autónomo que permita a los estudiantes seguir aprendiendo a lo largo de su ejercicio profesional, especialmente aquellos conocimientos que no pudieron ser enseñados durante la etapa de escolaridad (por tiempo o enfoque de la asignatura) y otros que se vuelven obsoletos con el paso de la historia (Carlino, 2004a). Por tanto, el aprendizaje para la vida se logra en la medida en que se propicie la participación activa en las dinámicas específicas de cada campo disciplinar y se genere la apropiación del saber a través de la escritura.

Tales reflexiones configuran el concepto de alfabetización académica propuesto por Carlino en el 2005 y replanteado en 2013, a los cuales ya se hizo referencia en el primer apartado de este documento. Ahora bien, en su definición de 2013, Carlino resalta la necesidad del trabajo conjunto entre todos los actores de la comunidad educativa para el logro de las metas propuestas. De allí que interesa revisar tanto los diagnósticos y aprendizajes que se esperan de los estudiantes como las prácticas educativas que han de poner en marcha los docentes alrededor del texto escrito. A nivel de los estudiantes, básicamente se trata de resaltar que desconocen las prácticas letradas de las comunidades académicas, pues nunca antes han sido preparados para ello. Se resalta entonces la necesidad de establecer procesos de acompañamiento que orienten los modos de leer, escribir, aprender e investigar en las disciplinas específicas.

En cuanto al papel del docente, es claro que su dominio disciplinar le presenta las prácticas letradas como un conocimiento implícito y natural, que se adquiere solo por la difusión del saber en el aula. De modo que se requiere empezar el proceso de enseñanza de la lectura y la escritura académicas concientizando a los docentes de las disciplinas acerca de las prácticas culturales que configuran los saberes particulares; que actúen como guías, orientando hacia el desarrollo de categorías de análisis, puntos de vista para enfocar la lectura o el filtro para descartar detalles irrelevantes que fortalezcan la comprensión y la producción de textos (Carlino, 2005). Frente a la magnitud de la tarea, esta debe ser una responsabilidad compartida entre estudiantes, profesores e instituciones, que puede iniciarse con un trabajo en equipo, así como el desarrollo de programas interdisciplinarios de formación profesional respaldados por la universidad como institución (Carlino, 2005). Allí participarían docentes de las disciplinas que conocen sus prácticas, profesores de pedagogía que pueden orientar el diseño de ambientes de aprendizaje basados en dichas prácticas y maestros de lengua que dominan los principios generales de una buena comunicación y cómo lograrla según propósitos diversos.

Para terminar con las referencias hechas a los estudios de Carlino, conviene revisar, desde su perspectiva, la dicotomía entre cursos de lengua y cursos disciplinares con alto grado de acompañamiento en procesos de lectura y escritura. Los primeros, son para Carlino un mecanismo adecuado para subsanar los vacíos que traen los estudiantes desde el nivel básico y que, obviamente, se requieren durante la formación profesional; por ejemplo, una actitud metacognitiva de detectar cuando no se está seguro de la gramática o la ortografía, el reconocimiento del propósito y la audiencia y su consecuente consciencia retórica que permita encauzar el texto hacia el logro de dicho propósito, respondiendo a las expectativas del lector potencial (Carlino, 2013). Además, puede formar a nivel del contacto efectivo con la bibliografía, los métodos y los problemas conceptuales de un determinado campo científico-profesional, la actitud reflexiva hacia la producción y comprensión textual o la toma de conciencia de lo que tienen en común muchos de los géneros académicos. Sin embargo, "no evita las dificultades discursivas y estratégicas cuando los estudiantes se enfrentan al desafío de pensar por escrito las nociones que se estudian en las asignaturas" (Carlino, 2005, p. 22). 
Se encuentra entonces a lo largo de la obra de Carlino un enfoque socioconstructivista: social, en la medida en que resalta el texto escrito como perteneciente a comunidades científicas particulares en un juego de interacciones desde las cuales tanto el texto como la sociedad impactan de manera recíproca; de modo que la clave de la comprensión y producción adecuada de los textos se produce dentro de cada comunidad. Constructivista, puesto que resalta el papel del lenguaje para aprender los conceptos y los códigos de la disciplina, lo cual permite al estudiante continuar aprendiendo a lo largo de la vida, actualizando el saber y sometiéndolo a procesos de investigación que contribuyan a la dinámica científica.

El siguiente autor con mayor índice de recurrencia es Van Dijk. A partir de sus estudios sobre lingüística textual y análisis crítico del discurso se revisan los textos abordados en el aula y se proponen intervenciones didácticas tendientes a desarrollar los procesos de comprensión y producción desde un enfoque socio-cognitivo. De allí se resalta el estudio del texto como unidad de análisis, más allá de la oración, enfatizando en su contenido y no solo en su forma y estructura; como resultado, la enseñanza del lenguaje ya no se enfoca en la gramática, sino en el contexto donde se desarrolla el acto comunicativo, es decir, la lengua en uso. Aparecen entonces términos como "contexto", entendido como "una abstracción de la situación de enunciación que constituye el conocimiento compartido, por lo menos parcialmente, para los interlocutores y que permite la comunicación" (Van Dijk, 1992, p. 93). Al hacer evidentes los elementos extratextuales que determinan y son determinados por el texto escrito, se ingresa a concepciones como la "adecuación", más allá de la "corrección", y se ponen en juego una serie de conocimientos de tipo pragmático y social que van a determinar los intereses de enseñanza de los docentes de lengua, a nivel del énfasis en las comunidades discursivas. Es decir, al igual que con Carlino, se subraya el discurso como fenómeno social y cultural, con códigos particulares que necesitan ser enseñados, de modo que el estudiante pueda tomar conciencia de los roles e identidades con los cuales se usa el discurso en una situación real.
De Van Dijk se retoman también sus estudios sobre las estructuras del texto que construyen el sentido. Interesa entonces analizar en el aula el nivel de significado global, representado en las macroproposiciones, y el nivel local de las microproposiciones, que se presentan en una unidad de contenido. Pero de manera especial, son más recurrentes las remisiones a las macrorreglas como mecanismo para "organizar y reducir grandes cantidades de información" (Van Dijk, 1980, p. 81), pues se considera el ejercicio de síntesis como determinante para el aprendizaje de los saberes disciplinares, y también para identificar las proposiciones temáticas que conllevan rasgos ideológicos susceptibles de ser analizados como mecanismo para la formación de un lector crítico. En este último sentido, se retoma la concepción del autor acerca del análisis crítico del discurso, centrado en "los problemas sociales, y en especial en el papel del discurso en la producción y en la reproducción del abuso de poder o de la dominación [...] desde una perspectiva que sea coherente con los mejores intereses de los grupos dominados" (Van Dijk, 2003, p. 144).

Sin embargo, cabe señalar que Van Dijk plantea una "teoría multidisciplinaria del contexto", cuya definición aún no se incluye en las investigaciones de los autores colombianos, y que resalta el papel de la subjetividad en la comprensión y producción del lenguaje. Así, este autor afirma que

[...] los contextos no son dimensiones objetivas de las situaciones sociales -como el género, la edad o la clase social- que causan o determinan las propiedades del discurso, sino definiciones subjetivas que realizan los participantes acerca de las dimensiones realmente relevantes de estas situaciones. (2011, p. 145)

Dichos contextos se incluyen en las representaciones autobiográficas de la memoria episódica y se configuran como modelos mentales, por tanto, requieren ser explicitados en términos cognitivos.

Por otro lado, con un enfoque comunicativo de la lengua, más centrado en la sociología y la corrección de textos, Cassany aparece como otro de los autores con mayor índice de citación en los documentos estu- 
diados. En efecto, sus trabajos se encuentran más centrados en la dinámica de la escritura, y se enfocan en orientaciones didácticas para producir los textos que circulan tanto en la vida diaria como en la academia (Cassany, 1988). Tales orientaciones son retomadas por los docentes universitarios para diseñar sus intervenciones. Propone, por ejemplo, reconocer el valor democrático de la escritura y, desde allí, entender su dimensión (Cassany, 1995). Asimismo, reflexiona en torno al proceso de escritura que al principio se torna sin orden ni lógica y es esa precisamente la tarea del escritor: "limpiar la materia prima, seleccionar las ideas pertinentes, ordenarlas, tapar huecos y elaborar una estructura. La tarea implica tomar decisiones relevantes sobre el enfoque que tendrá el escrito y, en definitiva, sobre su eficacia" (Cassany, 1988, p. 71). A nivel de la didáctica, recomienda el trabajo cooperado, dentro de lo que denomina "comunidad de práctica" (2008) como la posibilidad de compartir propósitos y un contexto cognitivo con otros, con el fin de desarrollar un repertorio propio de géneros discursivos para construir identidad.

Nuevamente, sus aportes permiten justificar la enseñanza de la lectura y la escritura en el contexto de las disciplinas, argumentando que "ser un buen abogado, un buen ingeniero o un buen médico es, también, ser un buen lector y autor de los textos propios de estas disciplinas" (Cassany y Morales, 2009, p. 110). Se resalta además, por un lado, que enseñar a leer y escribir los textos especializados es una responsabilidad de la universidad; por otro lado, que se trata de una tarea ardua no natural. Cassany comparte con Carlino la idea de incluir las prácticas discursivas en las disciplinas, de modo que el estudiante se involucre directamente en su cultura académica y profesional, facilitando el desarrollo de su competencia discursiva (Cassany, Luna y Sanz, 1994). De otro lado, se encuentra con la tendencia de Van Dijk al concebir la enseñanza de la lengua más allá de la gramática formal, y muestra que escribir es ser capaz de expresar información de manera coherente y correcta para que la entiendan otras personas" (Cassany, 1995, p. 3).

Los demás autores referenciados en los documentos aparecen con una recurrencia proporcional mucho menor como para ser generalizados. En esta heterogeneidad de documentos se encuentran, entre otros, los que enumeramos en la tabla 2.

\begin{tabular}{|c|c|}
\hline Tema & Referencia \\
\hline Análisis del discurso & $\begin{array}{l}\text { Halliday, M. (1982). El lenguaje } \\
\text { como semiótica social. México: } \\
\text { Fondo de Cultura Económica. }\end{array}$ \\
\hline $\begin{array}{l}\text { Teoría francesa de } \\
\text { la enunciación }\end{array}$ & $\begin{array}{l}\text { Martínez, M. C. (2002). } \\
\text { Estrategias de lectura y } \\
\text { escritura de textos académicos. } \\
\text { Cali: Universidad del Valle. }\end{array}$ \\
\hline $\begin{array}{l}\text { Análisis del discurso } \\
\text { como interdisciplina }\end{array}$ & $\begin{array}{l}\text { Calsamiglia, H. y Tusón, } \\
\text { A. (1999). Las cosas del } \\
\text { decir. Madrid: Ariel. }\end{array}$ \\
\hline $\begin{array}{l}\text { Psicogénesis de } \\
\text { la escritura }\end{array}$ & $\begin{array}{l}\text { Ferreiro, E. (1997). } \\
\text { Alfabetización: teoría y } \\
\text { práctica. México: Siglo xxı. }\end{array}$ \\
\hline Psicología cognitiva & $\begin{array}{l}\text { Castelló, M. y Monereo, C. } \\
\text { (1996). Un estudio empírico } \\
\text { sobre la enseñanza y } \\
\text { aprendizaje de estrategias } \\
\text { para la composición escrita de } \\
\text { textos argumentativos. Infancia } \\
\text { y Aprendizaje. 74, 39-55. }\end{array}$ \\
\hline Sociorretórica & $\begin{array}{l}\text { Bazerman, C. et ál. (2005). } \\
\text { Writing to learn. En Reference } \\
\text { guide to writing across the } \\
\text { curriculum (pp. 57-65). } \\
\text { Indiana: Parlor Press. }\end{array}$ \\
\hline Teoría sociocultural & $\begin{array}{l}\text { Vygotsky, L. (1977). } \\
\text { Pensamiento y lenguaje. } \\
\text { Buenos Aires: La Pléyade. }\end{array}$ \\
\hline
\end{tabular}

Frente a esta heterogeneidad quedan de manifiesto las múltiples posibilidades de trabajo desde el texto escrito, a partir de cada uno de los enfoques expuestos que, en lugar de oponerse, se complementan. Pero llama la atención también la necesidad de adelantar estudios desde el interés específico de cada campo del conocimiento, que respondan a los requerimientos de sus propios discursos. Sin embargo, la tarea de enseñar lengua en las disciplinas lleva consigo una triple tarea, en la cual han de converger tres orientaciones científicas: (1) La lingüística, como ciencia del texto, en palabras de Van Dijk, y que, en sí misma, cuenta con una multiplicidad de enfoques que buscan contribuir a la total comprensión del sistema de la lengua en el marco del uso intencional. (2) Las disciplinas de 
las distintas áreas de formación profesional, cada una de ellas poseedora de una tradición epistemológica que ya en sí mismas constituyen un universo de conocimientos construidos a lo largo de la historia de la humanidad. (3) La didáctica, encargada de transponer los saberes científicos en procesos y contenidos para ser enseñados, un mecanismo que varía en relación con los enfoques, los contextos y los objetivos de enseñanza. Como se ve, se trata de crear una sinergia entre saberes científicos de amplia envergadura, de la cual aún no existe una comunidad académica.

Por otro lado, las investigaciones pocas veces referencian de manera explícita y detallada las teorías lingüísticas y didácticas que han servido como base para la reflexión o la intervención. Es claro que los documentos estudiados, mayoritariamente publicados en formato de ponencia, requieren un alto nivel de síntesis, sin embargo también se puede observar cómo se describe ampliamente la justificación del trabajo y los resultados. Asimismo, poca o ninguna mención se hace a los avances logrados por el movimiento de escritura a través del currículo (WAC) y escribir en las disciplinas (WID), la sociorretórica, el interaccionismo sociodiscursivo o la lingüística sistémico funcional, de la cual deriva la pedagogía de género de la Escuela de Sidney; tampoco sus aplicaciones por grupos de investigación de las universidades latinoamericanas; todos ellos procesos de intervención en el aula desde donde se trabaja la enseñanza de la lengua, no como tipos de texto, sino como clases de acciones sociales que se realizan en torno a textos.

\section{Conclusiones}

Las investigaciones revisadas confluyen en una clara conciencia acerca de la necesidad de vincular procesos de enseñanza de la lectura y la escritura en relación directa con la formación en las disciplinas que constituyen los programas académicos en las universidades. Lo anterior se justifica por cuanto la preparación profesional requiere el dominio de discursos y saberes especializados que solo pueden adquirirse a partir de prácticas situadas y contextualizadas.
En este sentido, los documentos abordados subrayan los pocos resultados obtenidos en los cursos de lengua durante los primeros semestres de formación universitaria como consecuencia de su falta de vinculación con los saberes y dinámicas propias de cada campo disciplinar (Gonzálezy Vega, 2010; Henao y Londoño, 2014; López y Molano, 2007). Asimismo, incluso los estudiantes resaltan la necesidad de transversalizar el componente de competencias comunicativas a lo largo de la malla curricular (Calle, 2015). Cabe resaltar que los beneficios de los cursos iniciales siguen siendo necesarios. Pero se requiere una reflexión profunda en torno al enfoque que manejan, los contenidos que se proponen y la metodología con la que se orientan, pues claramente deben estar vinculados a las actividades académicas propias de la Educación Superior a lo largo de la carrera.

A pesar de los resultados de las investigaciones, en las universidades colombianas continúa una clara tendencia a fomentar cursos remediales, por encima de institucionalizar el trabajo interdisciplinar entre el docente de lengua y el docente de la disciplina. Tal situación puede estar respondiendo a que se trata de un discurso todavía sin fuerza de cambio a nivel institucional, pues implica un fuerte reajuste en áreas de planeación curricular y contratación docente, difíciles de asumir en las universidades.

Con respecto a los enfoques teóricos y metodológicos que puedan orientar de manera efectiva la didáctica de la lengua disciplinar en la universidad, no existen bases teóricas claras ni homogéneas entre las investigaciones realizadas. Las referencias bibliográficas y el marco teórico de los documentos estudiados transitan entre estudios didácticos, cognitivos, gramaticales, discursivos y legales que llevan los procesos de intervención por caminos dispares, aunque en persecución del mismo objetivo. A nivel metodológico, se adelantan esfuerzos de diagnóstico e intervención, en ocasiones desde la posibilidad de un trabajo en equipo entre los docentes de lengua y los docentes especialistas, en ocasiones únicamente desde la clase de lengua trayendo materiales de las disciplinas o respondiendo a preocupaciones de otros docentes en relación con las falencias de los estudiantes en el dominio de habilidades básicas. 
Con el ánimo de contribuir a superar estas tensiones entre la didáctica del lenguaje y los saberes disciplinares, se propone iniciar con el papel que ha de desempeñar el docente de lengua, en dos sentidos específicos: el estudio de los textos disciplinares y el acompañamiento a los docentes de los distintos programas académicos en sus ejercicios de enseñanza relacionados con el texto escrito. Con respecto a la primera tarea, es redundante afirmar que se lee de manera distinta en la Educación Básica y en la universidad, y al mismo tiempo, que se lee y escribe de manera particular en cada área del saber; pero lo que aún no se conoce a profundidad es cómo, por qué y para qué se lee y se escribe en las disciplinas. Se ha avanzado en el reconocimiento de los rasgos que diferencian los textos escolares de los documentos de nivel universitario, pero aún es corto el camino recorrido en materia de las particularidades discursivas de cada disciplina. Al decir de González y Vega "hay todo un mapa de formas de leer y de escribir en las universidades que todavía no presentan un rostro reconocible para que los estudiantes identifiquen los caminos por los que deben transitar en este sentido" (2010, p. 104).

Este conocimiento lo poseen los especialistas pero de manera muchas veces inconsciente, de modo que se hace difícil didactizarlo. El reconocimiento de tales discursos requiere "indagaciones de corte lingüístico y etnográfico" (Carlino, 2013, p. 372), pero también de un proceso de gestión con documentos disciplinares en marcos de enseñanza y aprendizaje, al que se le denomina "análisis didáctico del discurso" (Rojas, 2014b), es decir, la posibilidad de un trabajo colaborativo entre el docente de lengua y el docente de la disciplina, que permita comprender las dimensiones textual y discursiva de los textos especializados, para generar desde allí posibilidades de trabajo en el aula que evidencien "las relaciones de poder y las relaciones ideológicas que se tejen en los textos académicos" (Méndez, 2008, p. 116). Conocer las características discursivas de los documentos que se leen y se escriben en cada programa contribuirá no solo a tomar conciencia del papel del lenguaje, sino, también, a establecer mecanismos de trabajo en el aula tendientes a fomentar el dominio del texto escrito, tanto para el aprendizaje autónomo como para el desarrollo de la conciencia crítica.

Asimismo, los conocimientos derivados de esta caracterización discursiva podrán servir como base para la formación de maestros disciplinares a nivel de lectura y escritura, es decir, si el conocimiento discursivo de los docentes es inconsciente, hacerlo explícito será la base para el diseño de mecanismos didácticos que permitan orientar sistemáticamente a los estudiantes por los senderos de los textos especializados. Pero para lograrlo, se requiere problematizar aspectos complejos de resistencia al cambio en la enseñanza usual (por ejemplo, el dominio de la clase magistral en la clase universitaria); la autoimagen profesional del docente, quien requiere asumir una actitud de aprendizaje permanente; el trabajo en equipo, condicionado por los tiempos y actividades institucionales; los límites entre profesiones y profesionales (de la lengua y de la disciplina particular), que evidencian la brecha existente entre los distintos tipos de comunidades científicas; o los espacios y currículos de formación docente donde se les prepare para didactizar los textos disciplinares y trabajar con otros docentes que no pertenecen al área de lengua.

Hacen falta entonces investigaciones de mayor impacto que trasciendan el nivel diagnóstico (Castañeda y Henao, 2005) y se encaminen hacia reflexiones desde la didáctica y desde la lingüística en busca de alternativas para la formación de lectores y escritores en el ámbito universitario. Al respecto, el trabajo del grupo Prodeac en Argentina se constituye en una iniciativa pionera que vincula claramente los postulados de la lingüística sistémicofuncional y su derivada pedagogía de género, para utilizarla como base epistemológica en la formación de lectores y escritores en las disciplinas (Moyano, 2010; Natale, 2013; Navarro, 2014). 


\section{Referencias bibliográficas}

Cadena, S.; Narváez, E. y Chacón, M. (2007). Alfabetización académica: una de las responsabilidades de la Educación Superior. I Encuentro Nacional de Discusión sobre Políticas Institucionales para el Desarrollo de la Lectura y la Escritura en la Educación Superior. Ascun y Red Nacional de Discusión sobre Lectura y Escritura en Educación Superior. Universidad Sergio Arboleda.

Calle, M. et ál. (2015). Competencias Comunicativas en Ingeniería: Caso Estudiantes de Último Semestre. II Congreso Internacional Lectura y Escritura en la Sociedad Global. Universidad del Norte.

Calsamiglia, H. y Tusón, A. (1999). Las cosas del decir. Madrid: Ariel.

Camargo, Z. (2006). La enseñanza/aprendizaje del español (lengua materna) con fines académicos y profesionales. Una propuesta didáctica dirigida a profesores de programas no humanísticos de la Universidad del Quindío (tesis doctoral). Universidad Complutense de Madrid.

Carlino, P. (2002). Alfabetización académica: un cambio necesario, algunas alternativas posibles. Educere. Investigación, 6(20), 409-420.

Carlino, P. (2003a). Leer textos científicos y académicos en la Educación Superior: obstáculos y bienvenidas a una cultura nueva. Uni-Pluri/Versidad, 3(2), 17-23.

Carlino, P. (2003b). Alfabetización académica: un cambio necesario, algunas alternativas posibles. Educere, Revista Venezolana de Educación, 6(20), 409-420. Recuperado de www.saber.ula.ve/bitstream/123456789/19736/1/articulo7.pdf.

Carlino, P. (2004a). ¿De qué modos incentivar en nuestras instituciones la responsabilidad compartida por cómo se lee y se escribe en la universidad/institutos de formación docente, IFD? I Congreso Internacional Educación, Lenguaje y Sociedad. Universidad Nacional. Recuperado de http://www.fchst.unlpam. edu.ar/iciels/256.pdf.

Carlino, P. (2004b). El proceso de escritura académica: cuatro dificultades de la enseñanza universitaria. Educere Investigación, 8(26), 321-327.

Carlino, P. (2005). Escribir, leer y aprender en la universidad. Una introducción a la alfabetización académica. Buenos Aires: Fondo de Cultura Económica.

Carlino, P. (2007). ¿Qué nos dicen hoy las investigaciones internacionales sobre la escritura en la universidad?
Conferencia invitada en el I Encuentro Nacional de Discusión sobre Políticas Institucionales para el Desarrollo de la Lectura y la Escritura en la Educación Superior, Bogotá: Ascun y Red Nacional de Lectura y Escritura en Educación Superior.

Carlino, P. (2010). Estudiar, escribir y aprender en universidades australianas. Textura, 6(9) 11-33.

Carlino, P. (2011). Leer y escribir en las ciencias sociales en universidades argentinas. Revista Contextos de Educación. Recuperado de www.hum.unrc.edu.ar/ publicaciones/contextos.

Carlino, P. (2013). Alfabetización académica diez años después. Revista Mexicana de Investigación Educativa, 18(57), 355-381.

Cassany, D. (1988). Describir el escribir. Cómo se aprende a escribir. Barcelona: Paidós.

Cassany, D. (1995). La cocina de la escritura. Barcelona: Anagrama.

Cassany, D. (2008). Prácticas letradas contemporáneas. México: Ríos de tinta.

Cassany, D.; Luna, M. y Sanz, G. (2000). Enseñar lengua. Barcelona: Graó.

Cassany, D. y Morales, O. (2009). Leer y escribir en la universidad: los géneros científicos. En D. Cassany, (comp.). Para ser letrados (pp. 109-128). Barcelona: Paidós.

Chomsky, N. (1965). Aspects of the theory of syntax. Cambridge: MIT Press.

Castañeda, L. y Henao, J. (2005). La lingüística textual y la cultura escrita en la Universidad. Zona Próxima, 6, 12-31.

Cisneros, M. (2014). Base internacional bibliográfica sobre lectura y escritura. Recuperado de http:// www.utp.edu.co/vicerrectoria/investigaciones/ publicaciones-lectura-escritura/.

Cisneros, M. y Muñoz, C. (2014). Tras las huellas de las investigaciones sobre lectura y escritura en la universidad. Pereira: Universidad Tecnológica de Pereira.

Coronado, F. y Barragán, D. (2007). El canon de los 100 libros: estrategia para la consolidación de una política de lectura en la Universidad de la Salle. I Encuentro Nacional de Discusión sobre Políticas Institucionales para el Desarrollo de la Lectura y la Escritura en la Educación Superior. Ascun y Red Nacional de Discusión sobre Lectura y Escritura en Educación Superior. Universidad Sergio Arboleda. 
Cuesta, D.; Rodríguez, A. y Sandoval, M. (2014). Experiencia del grupo de apoyo a la lectura y la escritura de la facultad de salud de la Universidad del Valle. Recuperado de http://media.utp.edu.co/referenciasbibliograficas/uploads/referencias/ponencia/ m422pdf-nVBdT-articulo.pdf.

De Castro, A. et ál. (2015). Propuesta pedagógica: fortalecimiento de las competencias argumentativas en Ingeniería. Ponencia presentada en el II Congreso Lectura y Escritura en la Sociedad Global. Universidad del Norte.

Duque, M.I. (2007). Competencias comunicativas en la UEAN. Ponencia presentada en el I Encuentro Nacional sobre Políticas Institucionales para el Desarrollo de la Lectura y la Escritura en la Educación Superior.

Echeverri, I. (2015). Escritura como estrategia didáctica en la Universidad Icesi (Cali, Colombia). Ponencia presentada en el II Congreso Lectura y Escritura en la Sociedad Global. Universidad del Norte.

Escobar, N. (2013). Los procesos de la lectura y la escritura en el área de ingeniería de procesos. Memorias Congreso Cátedra Unesco para la Lectura y la Escritura. Universidad de Cartagena.

Escobar, N. (2014). El rastreo conceptual como estrategia para la producción textual. Recuperado de http:// media.utp.edu.co/referencias-bibliograficas/uploads/ referencias/ponencia/m705pdf-FaDmG-articulo.pdf.

García, D.; Nieto, N. y Vera, A. (2014). Integración de la lectura y la escritura en el curso de laboratorio de dispositivos electrónicos de ingeniería electrónica. Ponencia presentada en el v Encuentro Internacional y Iv Nacional de Lectura y Escritura en la Educación Superior. Universidad del Valle.

Gómez, D. (2004). El cambio de concepción sobre escritura del asesorado tras la revisión entre pares: una experiencia del grupo de apoyo para la lectura y escritura en la Facultad de Ingeniería. Recuperado de http://www.utp.edu.co/vicerrectoria/investigaciones/publicaciones-lectura-escritura/referencia/ ver/1319.

Gómez, O. (2010). Actos pedagógicos y estrategias mediadoras de rendimiento académico para fortalecer competencias de lectura y escritura de los estudiantes del programa de Contabilidad Financiera de las Unidades Tecnológicas de Santander. Ponencia presentada en el VI Congreso Internacional de la Cátedra Unesco. Universidad del Norte.
Gómez, A. (2015). Aprendizaje de la escritura periodística desde el análisis crítico del discurso. Ponencia presentada en el II Congreso Lectura y Escritura en la Sociedad Global. Universidad del Norte.

González, B. y Vega, V. (2010). Prácticas de lectura y escritura en la universidad. El caso de cinco asignaturas de la Universidad Sergio Arboleda. Bogotá: Universidad Sergio Arboleda.

Gordillo, A. y Restrepo B, J. (2014). Comprensión de lectura y aprendizaje de las matemáticas. Ponencia presentada en el v Encuentro Internacional y vi Nacional de Lectura y Escritura en Educación Superior, Bucaramanga.

Henao, J. et ál. (2011). Niveles de literacidad de los estudiantes de psicología de la Institución Universitaria de Envigado. Zona Próxima, 15, 54-77.

Henao, J. y Londoño, D. (2014). Leer y escribir en la universidad: El caso de la Institución Universitaria de Envigado. Íkala, Revista de Lenguaje y Cultura, 19(1), 27-45.

Herrera, J. (2014). La competencia comunicativa en el aprendizaje basado en problemas (АВP) para estudiantes de medicina. Disponible en: http://media.utp. edu.co/referencias-bibliograficas/uploads/referencias/ponencia/javier-herrerapdf-zsC50-articulo.pdf

Kintsch, W. (1998). Anagrama. Comprehension: A paradigm for cognition. New York: Cambridge University Press.

León, J. (2015). ¿Para qué leer y escribir en Arte Danzario?, un proyecto de aula. Ponencia presentada en el II Congreso Internacional Lectura y Escritura en la Sociedad Global. Universidad del Norte.

López, G. y Molano, L. (2007). Concepciones de profesores y estudiantes sobre la escritura académica en la Universidad Icesi. Lenguaje. Revista de la Escuela de Ciencias del Lenguaje de la Universidad del Valle, 35(1), pp. 119-146.

López, K. y Martínez, J. (2014). Escribir para aprender y comunicar en la asignatura Procesos de Ingeniería de Software. Trabajo colaborativo entre docentes de lengua $y$ docentes de las disciplinas. Ponencia presentada en el $v$ Encuentro Internacional y IV Nacional de Lectura y Escritura en la Educación Superior. Redlees.

Manyoma. E. y Gómez, Y. (2013). El plan lector: Una experiencia que nace para provocar la lectura interpretativay la producción escrita en jóvenes universitarios. Ponencia presentada en el Congreso Lectura y Escritura en la Sociedad Global. Universidad del Norte. 
Manyoma, E. (2015). Intervención didáctico-pedagógica para fortalecer las competencias genéricas de lectura y escritura en estudiantes universitarios. Ponencia presentada en el II Congreso Lectura y Escritura en la Sociedad Global. Universidad del Norte.

Mateos, M.; Martín, E.; Pecharromán, A.; Luna, M. y Cuevas, I. (2008) Estudio sobre la percepción de los estudiantes de Psicología de las tareas de lectura y escritura que realizan para aprender. Revista de Educación, 347, 255-274.

Méndez, P. (2008). La escritura de textos con fines académicos, una revisión de los textos de universitarios principiantes. En E. Narvaez y S. Cadena, (comps.). Los desafíos de la lectura y la escritura en la Educación Superior: Caminos posibles. Cali: Universidad Autónoma de Occidente.

Molina, V. (2014). Profe, ¿apuntamos eso o le tomamos foto? Los apuntes de clase y su relación con el aprendizaje en las disciplinas. Ponencia presentada en el V Encuentro Internacional y vi Nacional de Lectura y Escritura en Educación Superior, Bucaramanga.

Morales, A. y Restrepo, M. (2010). ¿Para qué se lee y se escribe en la Facultad de Mercadeo, Comunicación y Artes del Politécnico Grancolombiano? Informe de investigación.

Moyano, E. (2010). Escritura académica a lo largo de la carrera. Revista Signos, 43(74), 465-488.

Narvaja, E. (2010). “A modo de Prólogo”. En B. González y V. Vega. Prácticas de lectura y escritura en la universidad. El caso de cinco asignaturas de la Universidad Sergio Arboleda. Bogotá: Universidad Sergio Arboleda.

Natale, L. (2013). Integración de enfoques en un programa institucional para el desarrollo de la escritura académica y profesional. Revista Mexicana de Investigación Educativa, 18(58), 685-707.

Navarro, F. (coord.) (2014). Manual de escritura para carreras de humanidades. Buenos Aires: Universidad de Buenos Aires.

Ortega, M. y Sánchez, S. (2002). Enseñanza de estrategias de aprendizaje para desarrollar habilidades de escritura en estudiantes universitarios de licenciatura mediante la elaboración de textos argumentativos tipo protocolo de investigación. Ponencia presentada en el xxir Congreso Nacional de Lingüística, Literatura y Semiótica, Cali.
Osorio, R. y Arias, O. (2014). Lectura y escritura en el aprendizaje de la matemática. Ponencia presentada en el I Encuentro Nacional sobre Políticas Institucionales para el Desarrollo de la Lectura y la Escritura en la Educación Superior, Bogotá, Colombia.

Parra, J. (2013). Las asesorías pedagógicas plan lector, una estrategia de transversalización del conocimiento en la escuela internacional de marketing y administración de la Universidad Sergio Arboleda Santa Marta. Ponencia presentada en el Congreso Internacional Lectura y Escritura en la Sociedad Global. Universidad del Norte.

Pedraza, C. y Cabrera, M. (2014). Tareas de escritura como dinamizadoras de la formación investigativa: experiencia de un curso virtual. Ponencia presentada en el v Encuentro Internacional y vi Nacional de Lectura y Escritura en Educación Superior, Bucaramanga.

Peña, L. (2007). El Proyecto "Leer y escribir en la universidad". Ponencia presentada en el Encuentro Nacional sobre Políticas Institucionales para el Desarrollo de la Lectura y la Escritura en Educación Superior. Asociación Colombiana de Universidades-Ascun y Universidad Sergio Arboleda.

Pérez, P. (2006). ¿Cómo abordar la enseñanza de la lectoescritura en la Facultad de Medicina de la Universidad de Antioquia? Ponencia presentada en el III Encuentro sobre Lectura y Escritura en la Universidad Experiencias Significativas. Recuperado de http:// media.utp.edu.co/referencias-bibliograficas/uploads/ referencias/ponencia/palomapdf-J695j-articulo.pdf.

Pérez, M. y Rincón, G. (coords.) (2013). ¿Para qué se lee y se escribe en la universidad colombiana? Un aporte a la consolidación de la cultura académica del país. Bogotá: Colciencias y Universidad Javeriana.

Ramírez, R. y López, G. (2014). Elaboración de resúmenes, una estrategia de estudio en ingeniería. Recuperado de http://media.utp.edu.co/referencias-bibliograficas/uploads/referencias/ponencia/ricardoramirezpdf-XWY2o-articulo.pdf.

Redlees. (2014). Historia Red de Lectura y Escritura en Educación Superior. Recuperado de http://ascun. org.co/noticias/726/.

Rojas, I. (2013). Leer, escribir y hablar en la universidad: un reto de trabajo interdisciplinar. Ponencia presentada en el I Congreso Internacional Lectura y Escritura en la Sociedad Global. Universidad del Norte. 
Rojas, I. (2014a). Enseñar a leer en derecho. Análisis textual de la obra Cartas de batalla, crítica al constitucionalismo colombiano. Cuadernos de Lingüística Hispánica, 24, 87-104.

Rojas, I. (2014b). El análisis didáctico del discurso. Ponencia presentada en el xvir Congreso Internacional Asociación de Lingüística y Filología de América Latina. Joao Pessoa, Universidad de Paraiba, Brasil.

Rojas, I. (2015). El papel del docente de lengua en la formación para la lectura y la escritura disciplinar. Ponencia presentada en el II Congreso de Lectura y Escritura. Barranquilla: Universidad del Norte.

Scardamalia, M. y Bereiter, C. (1992). Dos modelos explicativos de los procesos de composición escrita. Infancia y Aprendizaje, 58, 43-64.

Stanovich, K. E. (1986). Matthew effects in reading: Some consequences of individual differences in the acquisition of literacy. Reading Research Quarterly, 21, 360-407.

Van Dijk, T. (1980). Estructuras y funciones del discurso. Madrid: Siglo XxI.

Van Dijk, T. (1992). La ciencia del texto. Barcelona: Paidós.

Van Dijk, T. (2003). La multidisciplinaridad del análisis crítico del discurso: un alegato en favor de la diversidad. En R. Wodak y M. Meyer. Métodos de análisis crítico del discurso (pp. 143-177). Barcelona: Gedisa.

Van Dijk, T. (2011). Sociedad y discurso. Barcelona: Gedisa. 